\title{
BMJ Open The interaction of socioeconomic position and type 2 diabetes mellitus family history: a cross-sectional analysis of the Lifelines Cohort and Biobank Study
}

Sander K.R. van Zon, ${ }^{1}$ Harold Snieder, ${ }^{2}$ Ute Bültmann, ${ }^{1}$ Sijmen A. Reijneveld ${ }^{1}$

To cite: van Zon SK.R., Snieder H, Bültmann U, et al. The interaction of socioeconomic position and type 2 diabetes mellitus family history: a cross-sectional analysis of the Lifelines Cohort and Biobank Study. BMJ Open 2017;7:e015275. doi:10.1136/ bmjopen-2016-015275

- Prepublication history for this paper is available online. To view these files please visit the journal online (http://dx.doi. org/10.1136/bmjopen-2016015275).

Received 22 November 2016 Revised 1 March 2017 Accepted 13 March 2017

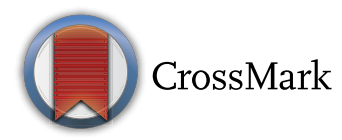

${ }^{1}$ Department of Health Sciences, Community and Occupational Medicine, University of Groningen, University Medical Center Groningen, Groningen, The Netherlands

${ }^{2}$ Department of Epidemiology, Unit of Genetic Epidemiology and Bioinformatics, University of Groningen, University Medical Center Groningen, Groningen, The Netherlands

Correspondence to drs Sander K.R. van Zon; s.k.r.van.zon@umcg.nl

\section{ABSTRACT}

Background Low socioeconomic position (SEP) and family history of type 2 diabetes mellitus (T2DM) contribute to increased T2DM risk, but it is unclear whether they exacerbate each other's effect. This study examined whether SEP reinforces the association of T2DM family history with T2DM, and whether behavioural and clinical risk factors can explain this reinforcement.

Methods We used cross-sectional data on 51725 participants from Lifelines. SEP was measured as educational level and was self-reported, just as family history of T2DM. T2DM was diagnosed based on measured fasting plasma glucose and glycated haemoglobin, combined with self-reported disease and recorded medication use. We assessed interaction on the additive scale by calculating the relative excess risk due to interaction (RERI).

Results ORs of T2DM were highest for males (4.37; 95\% $\mathrm{Cl} 3.47$ to 5.51$)$ and females $(7.77 ; 5.71$ to 10.56$)$ with the combination of low SEP and a family history of T2DM. The RERIs of low SEP and a family history of T2DM were 0.64 ( -0.33 to 1.62) for males and 3.07 (1.53 to 4.60 ) for females. Adjustment for behavioural and clinical risk factors attenuated associations and interactions, but risks remained increased.

Conclusion Low SEP and family history of T2DM are associated with T2DM, but they also exacerbate each other's impact in females but not in males. Behavioural and clinical risk factors partly explain these gender differences, as well as the associations underlying the interaction in females. The exacerbation by low SEP of T2DM risks in T2DM families deserves attention in prevention and community care.

\section{INTRODUCTION}

Type 2 diabetes mellitus (T2DM) is a common chronic health condition with an estimated prevalence of $9.8 \%$ in males and $9.2 \%$ in females. ${ }^{12}$ Globally, the number of people with T2DM has increased during the past decades from 153 million in 1980 to 347 million in 2008 and is estimated to rise to 439 million in 2030. ${ }^{12}$ Moreover, between 1990 and 2010, T2DM was the non-communicable disease
Strengths and limitations of this study

- This study examines the likely but largely unexamined biological interaction between socioeconomic position and family history of type 2 diabetes mellitus (T2DM) on T2DM occurrence.

- Objective measures of fasting plasma glucose, glycated haemoglobin and clinical risk factors for T2DM were obtained from 51725 participants.

- Results are based on a population-based study sample and generalisable to the general population.

- The cross-sectional study design does not allow for conclusions about causality, pointing to the need for longitudinal studies.

with the fastest increasing contribution to the burden of lost disability adjusted life years (DALYs). ${ }^{3}$ To tackle this major public health challenge, a better understanding of the interplay between modifiable and non-modifiable risk factors is needed.

Both low socioeconomic position (SEP) and family history of T2DM contribute to the increased risk of T2DM, ${ }^{4-13}$ but little is known about the impact of their co-occurrence. Interaction between low SEP and family history of T2DM may be likely because adverse circumstances related to a low SEP, like the co-occurrence of adverse health behaviours and clinical risk factors, ${ }^{14} 15$ may aggravate the familial predisposition for T2DM through the interplay of environment and genetics. ${ }^{16}$ Low SEP has been associated with a higher risk for T2DM in many studies. ${ }^{4-8}$ Poor health behaviours and clinical risk factors, such as obesity, partly explain this higher risk. ${ }^{4-717} 18$ Family history of T2DM has also consistently been associated with an increased risk for T2DM and is one of the most important factors predicting the disease. ${ }^{9-13}$ However, their co-occurrence seems to have escaped attention, despite its large potential impact. 
The impact of their co-occurrence in particular regards biological interaction, that is, two or more causes of disease that together assert their influence on disease risk. ${ }^{19}$ This interaction between low SEP and family history of T2DM may have large consequences for prevention and clinical care. For example, improved detection methods and a better tailoring of interventions to individual characteristics may help to decrease disease related morbidity and mortality. ${ }^{320}$ The possible aggravation of familial predisposition for T2DM by low SEP may differ between males and females through fundamental biological gender differences in genes and hormones in the development of T2DM. ${ }^{21}$ For example, some aspects of the control of metabolic homeostasis are regulated differently in males and females. ${ }^{21}$ Gender differences in the aggravation of familial predisposition for T2DM by low SEP may be important for the development of prevention and intervention programs and therefore need to be taken into account.

In the current study we examined the associations of SEP, family history of T2DM and their interaction on the occurrence of T2DM and whether these associations and interactions can be explained by behavioural and clinical risk factors.

\section{METHODS}

\section{Study design and sample}

The study sample was derived from the Lifelines Cohort Study. ${ }^{22}$ Lifelines is a multi-disciplinary prospective population-based Cohort study of 167729 persons living in the North of The Netherlands. Participants were recruited from November 2006 to December 2013 through their general practitioner or participating family members. Additionally, there was the option to self-register. The recruitment and collection of data have been described in detail elsewhere. ${ }^{22}$ Lifelines was conducted according to the guidelines in the Declaration of Helsinki, and all procedures involving human subjects were approved by the Medical Ethics Committee of the University Medical Center Groningen. Written informed consent was obtained from all participants during the visit at the research centre.

The current study uses data from participants who visited the Lifelines research centres between July 2012 and December 2013 for the baseline measurement $(n=52746)$, because family history of T2DM was only assessed during this period. A total of 51725 participants (98.1\% of the 52746 possible participants) were included in the analysis after excluding 1021 participants with missing data on SEP.

\section{Measures and procedures}

\section{Type 2 diabetes mellitus}

Participants were categorised as having T2DM if they had a measured fasting plasma glucose (FPG) $\geq 7.0 \mathrm{mmol} / \mathrm{L},{ }^{23}$ and/or a measured glycated haemoglobin (HbAlc) $\geq 6.5 \%$ $(48 \mathrm{mmol} / \mathrm{mol}),{ }^{23}$ and/or self-reported T2DM (ie, 'Do you have diabetes mellitus?', 'If you have diabetes, what type of diabetes do you have?' With answer categories: type 1 , type 2 , other, I do not know) in combination with self-reported medication use (ie, only tablets, only insulin, tablets and insulin, only a diet) and/or recorded T2DM medication use (ie, anatomical therapeutic chemical (ATC) codes A10A and A10B). ${ }^{24}$ The classification of T2DM diagnosis was made by a group of experts and was also used in previous studies that used Lifelines data. ${ }^{25} 26$

\section{Family history of T2DM}

Family history of T2DM was assessed using the following question: 'Do your parents, siblings or children have T2DM, or have they had T2DM?' with answer categories 'yes, my father', 'yes, my mother', 'yes, my brother(s) and/or sister(s)', 'yes, my child(ren)' and 'no'. Participants reporting having a first-degree relative (ie, parent, sibling or child) with T2DM were categorised as having a family history of T2DM.

\section{Socioeconomic position}

SEP was defined by educational level. Educational level was measured according to the International Standard Classification of Education with a single-item question regarding the highest educational level achieved. ${ }^{27}$ SEP was categorised into low (no education, primary education, lower or preparatory vocational education, lower general secondary education), medium (intermediate vocational education or apprenticeship, higher general senior secondary education or pre-university secondary education) and high (higher vocational education, university).

\section{Health-related behaviour}

Health-related behaviour concerned smoking status, alcohol consumption and physical activity. Smoking status was categorised as participants being a current smoker, former smoker or non-smoker. ${ }^{28}$ Alcohol consumption was categorised as participants being a non-drinker $(0$ drinks/day), light drinker ( $\leq 1 \mathrm{drink} /$ day $)$, moderate drinker ( $>1$ to 2 drinks /day) or heavy drinker ( $>2$ drinks / day). ${ }^{28}$ Physical activity was categorised as participants being inactive (0-2 days per week active for $\geq 30 \mathrm{~min})$, moderately active (3-4 days per week active for $\geq 30 \mathrm{~min}$ ) or active ( $\geq 5$ day per week active for $\geq 30 \mathrm{~min}$ ).

\section{Clinical risk factors}

Clinical risk factors concerned body mass index (BMI), waist circumference (WC) and hypertension. $B M I$ was calculated as weight $(\mathrm{kg})$ divided by height $(\mathrm{m})$ squared and used as an index of general weight status. Participants were categorised as underweight (BMI $<18.5)$, normal weight (BMI $\geq 18.5-\leq 24.9)$, overweight (BMI $\geq 25.0-\leq 29.9)$ or obese (BMI $\geq 30.0) .{ }^{29} W C$ was measured to the nearest $0.5 \mathrm{~cm}$ and used as an index of abdominal obesity. WC was categorised into no abdominal obesity $(\mathrm{WC}<102 \mathrm{~cm}$ in males, $\mathrm{WC}<88 \mathrm{~cm}$ in females) and abdominal obesity (WC $\geq 102 \mathrm{~cm}$ in males, $\mathrm{WC} \geq 88 \mathrm{~cm}$ in females) ${ }^{29}$ Hypertension diagnosis was based on measured blood pressure and 
recorded medication use. Participants with a measured $\mathrm{BP}>140 / 90 \mathrm{~mm} \mathrm{Hg}^{30}$ and participants with recorded antihypertensive medication (ie, ATC codes C02, C03, C07, $\mathrm{C} 08, \mathrm{C} 09)^{24}$ were categorised as hypertensive. Hypertension diagnosis was made by a group of experts and was also used in previous studies that used Lifelines data. ${ }^{256}$ All physical measurements were performed by trained research staff using standardised protocols and calibrated equipment. $^{22}$

\section{Statistical analyses}

First, we described baseline characteristics concerning socio-demographic, behavioural and clinical risk factors using descriptive statistics.

Second, we assessed associations of SEP and family history of T2DM on T2DM using logistic regression models. Potential modification of gender was assessed by adding an interaction term to the model. As significant modification was found $(\mathrm{p}=0.001)$, all analyses were stratified by gender. ORs with 95\% CIs were presented for each combination of SEP and family history of T2DM with the category of high SEP and no family history of T2DM serving as a reference category. ${ }^{31}$ These and following analyses were adjusted for age and age-squared. The age-squared term was added because the logit of the risk for T2DM may have a non-linear association with age.

Third, we measured interaction of SEP and family history of T2DM on the additive scale because the additive model best fits the method for assessing biological interaction. ${ }^{19} 3132$ To examine this interaction, multinomial logistic regression analyses were performed to obtain regression coefficients and the asymptotic covariance matrix. The recommended syntax by Andersson et $a l^{33}$ was used for these analyses. The model was specified as $i=1$ when low SEP was present and 0 when high SEP was present, and $j=1$ when family history of T2DM was present and 0 when family hstory of T2DM was not present. Participants with a medium SEP were thus not included in these analyses (ie, for them, separate analyses were performed). $\mathrm{OR}_{i j}$ was the $\mathrm{OR}$ in exposure category i.j. Three ORs (ie, $\mathrm{OR}_{11}^{i j}, \mathrm{OR}_{10}$ and $\mathrm{OR}_{01}$ ), with $\mathrm{OR}_{00}$ as the reference category, were estimated. The relative excess risk due to interaction (RERI) was calculated with the formula RERI $=\mathrm{OR}_{11}-\mathrm{OR}_{10}-\mathrm{OR}_{01}+1$ using the regression coefficients and covariance matrix obtained from the multinomial logistic regression analysis. ${ }^{33}$ The $95 \%$ CI for the RERI was calculated with the delta method using the algorithm by Andersson et al. ${ }^{33}{ }^{34}$ Interaction was present when the $95 \%$ CI did not include 0 . All analyses were repeated with medium SEP as risk factor (ie, comparing medium with high SEP, with medium SEP coded as 1 and high SEP as 0).

Fourth, as suggested by Knol and VanderWeele ${ }^{31}$ we also examined the associations of SEP and T2DM in categories of T2DM family history (ie, yes and no) and the associations of family history of T2DM and T2DM in categories of SEP (low, medium and high). These analyses offer additional information on the nature of the interaction effects.

Fifth, to examine whether behavioural and clinical risk factors explain the associations and interactions of SEP and T2DM family history with T2DM, we adjusted the basic model including age and age-squared stepwise for behavioural and clinical risk factors, including smoking status, alcohol consumption and physical activity (model 1 ), and further for general weight status and abdominal obesity (model 2) and finally also for hypertension (model 3). Participants with missing data on behavioural or clinical risk factors were omitted from the analyses. In the final model we had $12.8 \%$ missing data, mainly due to missing data on alcohol use (4.0\%), smoking $(8.0 \%)$ and physical activity (6.2\%), with for some participants having missing data on several behaviours. Data on clinical risk factors were mostly complete (ie, only $21(0.0 \%)$ missing values).

In sensitivity analyses, we examined whether the results were consistent if we based family history on parental T2DM only (ie, siblings and children not included in family history). We also repeated the analyses for maternal and paternal T2DM separately.

\section{RESULTS}

Baseline characteristics of the study population are shown in table 1. The proportion of participants with general obesity was three times higher in those with low SEP and a family history of T2DM (26.3\%) than in those with high SEP without a family history of T2DM $(8.9 \%)$. T2DM was most prevalent in males (figure 1), with an OR, corrected for age and age-squared, of 1.44 (95\% CI 1.31 to 1.58 ) compared with females. Across categories of SEP and family history of T2DM, the prevalence of T2DM was highest for those with a low SEP in combination with a family history of T2DM (12.8\% for males; $10.7 \%$ for females).

The associations and interactions of SEP and T2DM family history with T2DM are shown in table 2. The OR for T2DM was highest for females with low SEP and a family history of T2DM (OR: 7.77; 95\% CI: 5.71 to 10.56). A significant interaction between low SEP and a family history of T2DM was observed in females (RERI: 3.07; 95\% CI: 1.53 to 4.60 ) but not in males (RERI: 0.64; $95 \%$ CI: -0.33 to 1.62$)$. A similar gender difference in interactions was observed for medium SEP.

The underlying gender-specific ORs confirm this gender difference in interactions if looking per category of T2DM family history and per category of SEP (table 3). In general, the socioeconomic gradient in ORs for T2DM was steeper for females than for males, both for those with and without a family history of T2DM. Females without a family history of T2DM had a higher OR for low SEP (OR: 2.41; 95\% CI: 1.75 to 3.32 ) than males (OR: 1.39 ; $95 \%$ CI: 1.11 to 1.76 ), while the OR for medium SEP was similar. Females with a family history of T2DM had higher ORs for medium and low SEP compared with their male counterparts. Furthermore, 
Table 1 Baseline characteristics by SEP and family history of T2DM

\begin{tabular}{|c|c|c|c|c|c|c|}
\hline & \multicolumn{2}{|l|}{ High SEP } & \multicolumn{2}{|l|}{ Medium SEP } & \multicolumn{2}{|l|}{ Low SEP } \\
\hline & $\begin{array}{l}\text { No family } \\
\text { history of } \\
\text { T2DM } \\
(n=13386)\end{array}$ & $\begin{array}{l}\text { Family } \\
\text { history } \\
\text { of T2DM } \\
(n=2830)\end{array}$ & $\begin{array}{l}\text { No family } \\
\text { history of T2DM } \\
\text { ( } n=16367)\end{array}$ & $\begin{array}{l}\text { Family history } \\
\text { of T2DM } \\
(\mathrm{n}=4426) \\
\end{array}$ & $\begin{array}{l}\text { No family } \\
\text { history of T2DM } \\
(n=10376)\end{array}$ & $\begin{array}{l}\text { Family history } \\
\text { of T2DM } \\
(n=4340)\end{array}$ \\
\hline Age, years (mean, SD) & $42.0(12.7)$ & $47.6(11.5)$ & 39.9 (12.9) & $46.4(10.7)$ & $49.1(14.4)$ & $53.1(11.5)$ \\
\hline Gender (\% F) & 56.4 & 56.3 & 58.2 & 63.8 & 55.6 & 61.6 \\
\hline \multicolumn{7}{|l|}{ Smoking (\%) } \\
\hline Current smoker & 11.4 & 11.8 & 20.0 & 17.9 & 23.9 & 21.1 \\
\hline Former smoker & 28.7 & 35.0 & 28.4 & 34.3 & 37.2 & 40.3 \\
\hline Non-smoker & 59.9 & 53.2 & 51.7 & 47.8 & 38.9 & 38.6 \\
\hline \multicolumn{7}{|l|}{ Alcohol (\%) } \\
\hline Non-drinker & 11.8 & 14.5 & 16.6 & 20.7 & 21.4 & 25.4 \\
\hline Light drinker & 55.8 & 54.2 & 54.5 & 53.7 & 48.4 & 47.6 \\
\hline Moderate drinker & 24.4 & 24.4 & 20.3 & 18.7 & 19.9 & 19.1 \\
\hline Heavy drinker & 8.1 & 6.9 & 8.6 & 6.9 & 10.3 & 7.8 \\
\hline \multicolumn{7}{|l|}{ Physical activity (\%) } \\
\hline Inactive & 23.9 & 24.1 & 28.5 & 28.1 & 29.6 & 29.2 \\
\hline Moderately active & 28.5 & 25.7 & 25.4 & 25.6 & 24.5 & 23.5 \\
\hline Active & 47.6 & 50.2 & 46.1 & 46.3 & 46.0 & 47.3 \\
\hline BMI (mean, SD) & $24.9(3.8)$ & $26.1(4.2)$ & $25.6(4.2)$ & $27.1(4.7)$ & $26.6(4.5)$ & $27.7(4.7)$ \\
\hline \multicolumn{7}{|l|}{$\begin{array}{l}\text { General weight status } \\
(\%)\end{array}$} \\
\hline Underweight & 0.9 & 0.6 & 1.1 & 0.5 & 0.9 & 0.3 \\
\hline Normal weight & 56.3 & 43.9 & 48.7 & 34.4 & 37.4 & 29.0 \\
\hline Overweight & 33.9 & 39.9 & 37.2 & 42.4 & 42.6 & 44.3 \\
\hline Obese & 8.9 & 15.7 & 13.0 & 22.7 & 19.1 & 26.3 \\
\hline WC, cm F (mean, SD) & $82.3(10.8)$ & $86.2(11.9)$ & $84.4(12.0)$ & $89.7(13.0)$ & $88.3(12.6)$ & $92.2(13.0)$ \\
\hline WC, cm M (mean, SD) & $92.2(10.1)$ & $95.5(10.0)$ & $93.0(10.8)$ & $97.4(10.9)$ & $96.6(11.4)$ & $99.8(11.2)$ \\
\hline $\begin{array}{l}\text { Abdominal obesity } \\
\text { (\%) }\end{array}$ & 21.9 & 34.1 & 28.3 & 44.2 & 41.0 & 52.4 \\
\hline T2DM (\%) & 1.4 & 5.6 & 1.4 & 6.4 & 3.6 & 11.5 \\
\hline $\begin{array}{l}\text { Systolic blood } \\
\text { pressure, mm Hg } \\
\text { (mean, SD) }\end{array}$ & $122.1(14.7)$ & $125.2(15.5)$ & $123.3(14.1)$ & $126.1(15.1)$ & $128.3(15.9)$ & $130.3(16.1)$ \\
\hline $\begin{array}{l}\text { Diastolic blood } \\
\text { pressure, mm Hg } \\
\text { (mean, SD) }\end{array}$ & $72.4(9.3)$ & $74.4(9.7)$ & $72.4(9.3)$ & $74.3(9.4)$ & $74.8(9.7)$ & $75.5(9.6)$ \\
\hline Hypertension (\%) & 16.8 & 26.4 & 18.0 & 28.0 & 32.7 & 41.8 \\
\hline
\end{tabular}

BMI, body mass index; SEP, socioeconomic position; T2DM, type 2 diabetes mellitus; WC, waist circumference.

females with medium SEP had a higher OR for having a family history of T2DM than their male counterparts, while ORs were similar for high and low SEP.

Behavioural and clinical risk factors partly explained the associations and interactions of SEP and family history of T2DM with T2DM for males and females (table 4). In particular weight status in females appeared important for the increased OR for T2DM in low-SEP participants. The OR decreased from 6.01 to 4.09 after correction for general weight status and abdominal obesity. Interaction in females was still observed after adjustment for age, age-squared, smoking status, alcohol consumption and physical activity (RERI: 1.92 ; 95\% CI 0.54 to 3.30 ), and after additional adjustment for weight status (RERI: 1.05; $95 \%$ CI 0.02 to 2.09 ). However, the interaction was no longer statistically significant after additional adjustment for hypertension (RERI: 0.88; 95\% CI 


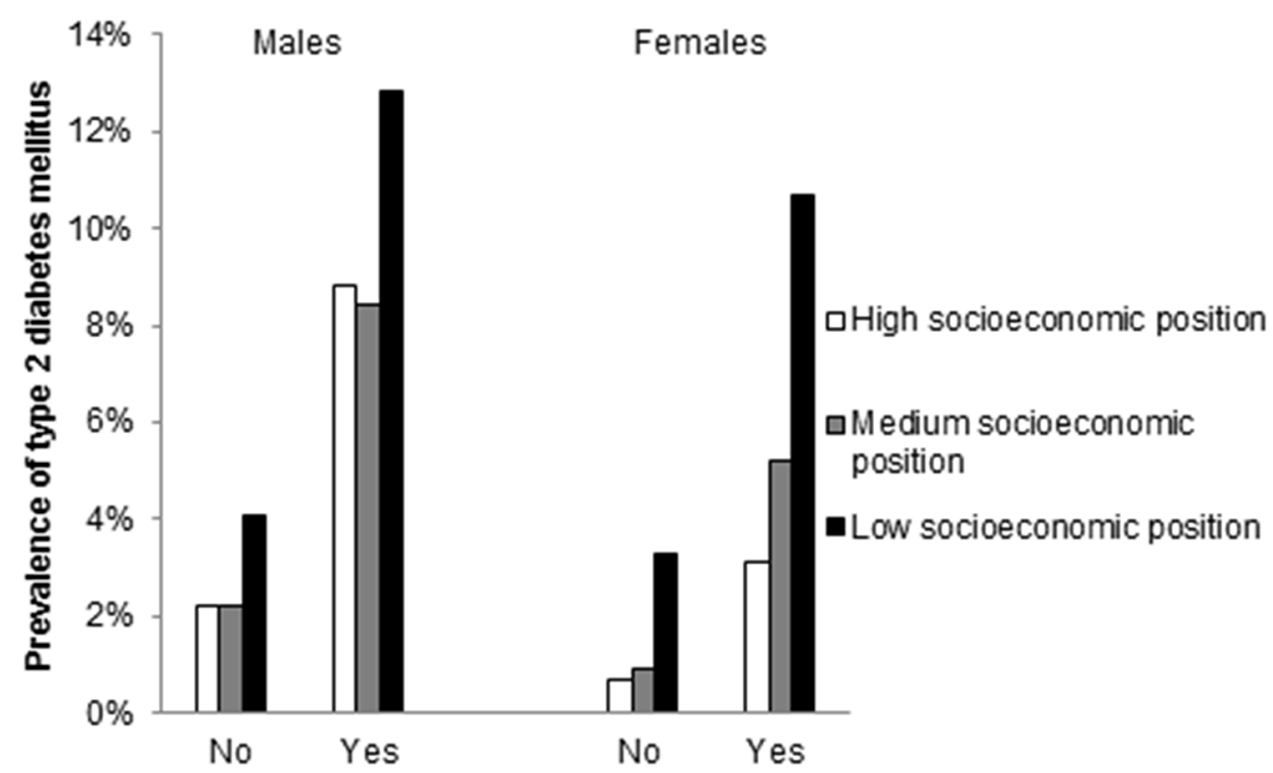

Type 2 diabetes mellitus family history

Figure 1 Prevalence of T2DM for males and females per socioeconomic category, by family history of T2DM.

-0.09 to 1.85$)$. Findings were almost similar for the interaction between medium SEP and family history of T2DM, but the RERI remained statistically significant after additional adjustment for hypertension.

Sensitivity analyses showed that the main findings remain consistent when using different categorisations for family history (table 5 ). The first part of table 5 shows the results of repeating the main analyses with family history based only on parental T2DM (ie, siblings and children not included in family history). Except for a small difference in the magnitude of associations and interactions, results were virtually identical to the main analyses. The second part of table 5 shows that findings are also essentially similar when repeating the analyses for maternal and paternal T2DM separately.

\section{DISCUSSION}

Our study shows that low SEP and family history of T2DM are separately associated with the occurrence of T2DM

Table 2 Associations and interactions of SEP and T2DM family history with T2DM, stratified by gender

\begin{tabular}{|c|c|c|c|c|c|c|}
\hline & \multicolumn{3}{|l|}{ Males } & \multicolumn{3}{|l|}{ Females } \\
\hline & n T2DM/n total & OR $(95 \% \mathrm{CI})$ & RERI (95\% Cl) & n T2DM/n total & OR (95\% Cl) & RERI $(95 \%$ Cl) \\
\hline \multicolumn{7}{|c|}{$\begin{array}{l}\text { No family history of } \\
\text { T2DM }\end{array}$} \\
\hline High SEP & $130 / 5835$ & 1.00 (ref) & & $52 / 7551$ & 1.00 (ref) & \\
\hline Medium SEP & $153 / 6843$ & $\begin{array}{l}1.28(1.01 \text { to } \\
1.63)\end{array}$ & & $82 / 9524$ & $\begin{array}{l}1.33 \text { (0.94 to } \\
1.89)\end{array}$ & \\
\hline \multicolumn{7}{|c|}{ Family history of T2DM } \\
\hline High SEP & $109 / 1236$ & $\begin{array}{l}3.34(2.55 \text { to } \\
4.37)\end{array}$ & & $49 / 1594$ & $\begin{array}{l}3.24(2.18 \text { to } \\
4.82)\end{array}$ & \\
\hline Medium SEP & $135 / 1604$ & $\begin{array}{l}3.72(2.89 \text { to } \\
4.80)\end{array}$ & $\begin{array}{l}0.41(-0.46 \text { to } \\
1.29)^{\unrhd}\end{array}$ & $147 / 2822$ & $\begin{array}{l}6.02 \text { ( } 4.36 \text { to } \\
8.32)\end{array}$ & $\begin{array}{l}2.77(1.48 \text { to } \\
4.06)^{\rrbracket}\end{array}$ \\
\hline
\end{tabular}

ORs are adjusted for age and age-squared.

${ }^{*}$ RERI T2DM for medium SEP.

†RERI T2DM for low SEP.

RERI, relative excess risk due to interaction; SEP, socioeconomic position; T2DM, type 2 diabetes mellitus. 
Table 3 Associations of SEP with T2DM per category of T2DM family history, and associations of T2DM family history with T2DM per category of SEP, stratified by gender

\begin{tabular}{|c|c|c|}
\hline & Males & Females \\
\hline & OR $(95 \% \mathrm{Cl})$ & OR $(95 \% \mathrm{Cl})$ \\
\hline & \multicolumn{2}{|c|}{ The association of SEP and T2DM per category of T2DM family history } \\
\hline \multicolumn{3}{|l|}{ No family history of T2DM } \\
\hline High SEP & 1 (ref) & 1.00 (ref) \\
\hline Medium SEP & 1.27 (1.00 to 1.62$)$ & $1.33(0.93$ to 1.88$)$ \\
\hline Low SEP & $1.39(1.11$ to 1.76$)$ & 2.41 (1.75 to 3.32$)$ \\
\hline \multicolumn{3}{|l|}{ Family history of T2DM } \\
\hline High SEP & 1.00 (ref) & 1.00 (ref) \\
\hline Medium SEP & $1.12(0.85$ to 1.47$)$ & 1.86 (1.33 to 2.59$)$ \\
\hline \multirow[t]{2}{*}{ Low SEP } & 1.30 (1.01 to 1.68$)$ & $2.43(1.76$ to 3.33$)$ \\
\hline & \multicolumn{2}{|c|}{ The association of T2DM family history and T2DM per category of SEP } \\
\hline \multicolumn{3}{|l|}{ High SEP } \\
\hline No family history of T2DM & 1.00 (ref) & 1.00 (ref) \\
\hline Family history of T2DM & 3.36 (2.56 to 4.42$)$ & 3.27 (2.19 to 4.90$)$ \\
\hline \multicolumn{3}{|l|}{ Medium SEP } \\
\hline No family history of T2DM & 1.00 (ref) & 1.00 (ref) \\
\hline Family history of T2DM & 2.93 (2.29 to 3.75$)$ & 4.52 (3.42 to 5.97 ) \\
\hline \multicolumn{3}{|l|}{ Low SEP } \\
\hline No family history of T2DM & 1.00 (ref) & 1.00 (ref) \\
\hline Family history of T2DM & 3.11 (2.52 to 3.84$)$ & 3.16 (2.60 to 3.84$)$ \\
\hline
\end{tabular}

ORs are adjusted for age and age-squared.

Some categories in this table are similar to those in table 2, but ORs may slightly differ because these result from within category analyses (ie, with a different size of the sample being analysed and therefore a slightly different correction for age and age-squared).

SEP, socioeconomic position; T2DM, type 2 diabetes mellitus.

and, more importantly, exacerbate each other's impact in females but not in males although at generally lower absolute rates in females than in males. The same gender difference in interaction was found for medium SEP, but to a lesser degree. Behavioural and clinical risk factors, especially weight status, partly explained these gender differences, as well as the associations underlying the interaction between low SEP and family history of T2DM in females.

We found that the combination of low SEP and having a family history of T2DM had a stronger association with T2DM than the sum of the associations of the separate factors in females, but not in males. Low SEP has been associated with adverse health behaviours and clinical risk factors in many previous studies, ${ }^{14}{ }^{15}$ and these factors are generally viewed as mediators in the relationship between low SEP and poor health. ${ }^{35}$ It seems likely that they aggravate the genetic predisposition for T2DM through the complex interplay of genetics and the environment, ${ }^{16}$ which in turn may lead to the development of T2DM. A possible explanation for the gender difference in this interaction effect may be that men and women have different coping styles in response to the knowledge of having a family history of T2DM. In general, women are more likely to engage in problem-focused coping styles. ${ }^{36}$
Females with a medium or high SEP and a family history of T2DM may therefore make better use of the knowledge of having a family history of T2DM than their male counterparts in adapting their preventive behaviour. However, the pathways leading to this gender difference definitely deserve further study.

Similar to previous studies, ${ }^{4-7} 1718$ associations and interactions of low SEP and family history of T2DM with T2DM were partly explained by behavioural and clinical risk factors. In particular, obesity in females explained the increased OR/RERI for T2DM in low-SEP participants. Nevertheless, significant ORs for T2DM remained for both males and females with a low SEP and a family history of T2DM even after adjustment for all behavioural and clinical risk factors. Other unmeasured risk factors may also play a role in the development of T2DM and may further explain the associations and interactions. For example, the physiologic response to chronic stress exposure in low SEP individuals may increase the risk for T2DM and may differ by gender. ${ }^{37}$

Our finding that family history of T2DM and low SEP were independently associated with T2DM is consistent with previous cross-sectional and longitudinal studies. ${ }^{4-13}$ A systematic review on the relation between SEP and T2DM incidence showed that people with low SEP have an 
Table 4 Associations and interactions of SEP and T2DM family history with T2DM, stratified by gender, and adjusted for behavioural and clinical factors*

\begin{tabular}{|c|c|c|c|c|}
\hline & Male & & Female & \\
\hline \multicolumn{5}{|l|}{ Model 1} \\
\hline \multicolumn{5}{|c|}{$\begin{array}{l}\text { No family history of } \\
\text { T2DM }\end{array}$} \\
\hline High SEP & 1.00 & & 1.00 & \\
\hline Low SEP & $1.28(1.00$ to 1.65$)$ & & 2.05 (1.46 to 2.88$)$ & \\
\hline \multicolumn{5}{|c|}{ Family history of T2DM } \\
\hline High SEP & 3.38 (2.54 to 4.51$)$ & & 3.05 (1.99 to 4.68$)$ & \\
\hline Medium SEP & 3.67 (2.80 to 4.82$)$ & $0.12(-0.81 \text { to } 1.05)^{\dagger}$ & 5.15 (3.65 to 7.27$)$ & $1.82(0.62 \text { to } 3.01)^{\dagger}$ \\
\hline Low SEP & 3.88 (3.01 to 4.98$)$ & $0.18(-0.82 \text { to } 1.18)^{\ddagger}$ & 6.01 (4.31 to 8.37$)$ & $1.92(0.54 \text { to } 3.30)^{\ddagger}$ \\
\hline High SEP & 1.00 & & 1.00 & \\
\hline Medium SEP & 1.15 (0.88 to 1.49$)$ & & 1.09 (0.75 to 1.57$)$ & \\
\hline Low SEP & $1.09(0.85$ to 1.41$)$ & & 1.54 (1.09 to 2.17$)$ & \\
\hline \multicolumn{5}{|c|}{ Family history of T2DM } \\
\hline High SEP & 3.29 (2.46 to 4.40$)$ & & $2.50(1.62$ to 3.85$)$ & \\
\hline Medium SEP & 3.06 (2.32 to 4.04$)$ & $-0.31(-1.16 \text { to } 0.53)^{\dagger}$ & $3.70(2.61$ to 5.24$)$ & $1.04(0.10 \text { to } 1.97)^{\dagger}$ \\
\hline Low SEP & $3.12(2.41$ to 4.03$)$ & $-0.27(-1.17 \text { to } 0.64)^{\ddagger}$ & 4.09 (2.92 to 5.72) & $1.05(0.02 \text { to } 2.09)^{\ddagger}$ \\
\hline \multicolumn{5}{|l|}{ Model 3} \\
\hline High SEP & 3.17 (2.36 to 4.25$)$ & & 2.38 (1.54 to 3.68$)$ & \\
\hline Medium SEP & 2.98 (2.25 to 3.94$)$ & $-0.25(-1.07 \text { to } 0.56)^{\dagger}$ & 3.47 (2.44 to 4.93$)$ & $0.93(0.04 \text { to } 1.81)^{\dagger}$ \\
\hline Low SEP & 3.02 (2.33 to 3.91$)$ & $-0.20(-1.08 \text { to } 0.68)^{\ddagger}$ & 3.69 (2.63 to 5.18$)$ & $0.88(-0.09 \text { to } 1.85)^{\ddagger}$ \\
\hline
\end{tabular}

*Adjustment regards:

Model 1: age, age-squared, smoking, alcohol consumption, physical activity.

Model 2: age, age-squared, smoking, alcohol consumption, physical activity, general weight status, abdominal obesity.

Model 3: age, age-squared, smoking, alcohol consumption, physical activity, general weight status, abdominal obesity, hypertension.

RERI, relative excess risk due to interaction; SEP, socioeconomic position; T2DM, type 2 diabetes mellitus.

†RERI T2DM for medium SEP.

†RERI T2DM for low SEP.

increased risk for T2DM, irrespective of the SEP indicator used. ${ }^{8}$ Although our findings might have differed somewhat for other indicators of SEP, it is likely that the main conclusions would be similar because all indicators for SEP measure a certain underlying social stratification. ${ }^{38}$ Moreover, education has been shown to best capture the effects of SEP in studies on other chronic diseases in The Netherlands, for example, in chronic kidney disease. ${ }^{39}$ T2DM may also affect SEP through a decrease in work participation, absenteeism and early retirement, ${ }^{40}$ but such a reverse causation is unlikely to explain our findings. Our measure of SEP, educational level, has usually been established long before T2DM develops and is therefore the SEP indicator least sensitive for reverse causation. This is important given the cross-sectional nature of our study.

In the current study, predisposition for T2DM was defined by family history of T2DM. T2DM predisposition may also be defined through a genetic risk score (GRS) based on risk loci obtained from genome-wide 
Table 5 Associations and interactions of SEP and different categorisations of T2DM family history with T2DM, stratified by gender

\begin{tabular}{|c|c|c|c|c|c|c|}
\hline & \multicolumn{3}{|l|}{ Males } & \multicolumn{3}{|l|}{ Females } \\
\hline & n T2DM/n total & OR $(95 \% \mathrm{Cl})$ & RERI $(95 \% \mathrm{Cl})$ & n T2DM/n total & OR (95\% Cl) & RERI $(95 \% \mathrm{Cl})$ \\
\hline \multicolumn{7}{|c|}{ Parental T2DM } \\
\hline \multicolumn{7}{|l|}{$\begin{array}{l}\text { No parental } \\
\text { T2DM }\end{array}$} \\
\hline High SEP & $130 / 5835$ & 1.00 (ref) & & $52 / 7551$ & 1.00 (ref) & \\
\hline Medium SEP & $153 / 6845$ & $\begin{array}{l}1.28(1.01 \text { to } \\
1.63)\end{array}$ & & $82 / 9527$ & $\begin{array}{l}1.33 \text { (0.94 to } \\
1.89)\end{array}$ & \\
\hline Low SEP & $188 / 4609$ & $\begin{array}{l}1.38 \text { (1.10 to } \\
1.74)\end{array}$ & & $191 / 5778$ & $\begin{array}{l}2.49 \text { (1.81 to } \\
3.42)\end{array}$ & \\
\hline \multicolumn{7}{|l|}{ Parental T2DM } \\
\hline High SEP & $87 / 1123$ & $\begin{array}{l}3.15(2.37 \text { to } \\
4.20)\end{array}$ & & $42 / 1471$ & $\begin{array}{l}3.23(2.13 \text { to } \\
4.89)\end{array}$ & \\
\hline Medium SEP & $120 / 1497$ & $\begin{array}{l}3.75 \text { (2.89 to } \\
4.88)\end{array}$ & $\begin{array}{l}0.32(-0.72 \text { to } \\
1.37)^{*}\end{array}$ & $132 / 2,654$ & $\begin{array}{l}5.92 \text { (4.27 to } \\
8.22)\end{array}$ & $\begin{array}{l}2.38(0.86 \text { to } \\
3.91)^{*}\end{array}$ \\
\hline Low SEP & $177 / 1463$ & $\begin{array}{l}4.43 \text { (3.48 to } \\
5.63)\end{array}$ & $\begin{array}{l}0.88(-0.15 \text { to } \\
1.91)^{\dagger}\end{array}$ & $247 / 2372$ & $\begin{array}{l}7.93 \text { (5.81 to } \\
10.81)\end{array}$ & $\begin{array}{l}3.17(1.50 \text { to } \\
4.84)^{\dagger}\end{array}$ \\
\hline \multicolumn{7}{|c|}{ Maternal T2DM } \\
\hline \multicolumn{7}{|c|}{$\begin{array}{l}\text { No } \\
\text { maternal T2DM }\end{array}$} \\
\hline High SEP & $131 / 5836$ & 1.00 (ref) & & $52 / 7553$ & 1.00 (ref) & \\
\hline Medium SEP & $153 / 6846$ & $\begin{array}{l}1.27(1.00 \text { to } \\
1.62)\end{array}$ & & $82 / 9530$ & $\begin{array}{l}1.33 \text { ( } 0.94 \text { to } \\
1.89)\end{array}$ & \\
\hline Low SEP & $189 / 4612$ & $\begin{array}{l}1.38(1.10 \text { to } \\
1.74)\end{array}$ & & $191 / 5780$ & $\begin{array}{l}2.44 \text { (1.78 to } \\
3.35)\end{array}$ & \\
\hline \multicolumn{7}{|l|}{ Maternal T2DM } \\
\hline High SEP & $62 / 618$ & $\begin{array}{l}3.74(2.71 \text { to } \\
5.17)\end{array}$ & & $24 / 744$ & $\begin{array}{l}3.20 \text { (1.95 to } \\
5.26)\end{array}$ & \\
\hline Medium SEP & $87 / 843$ & $\begin{array}{l}4.28 \text { (3.20 to } \\
5.72)\end{array}$ & $\begin{array}{l}0.28(-1.18 \text { to } \\
1.74)^{*}\end{array}$ & $90 / 1519$ & $\begin{array}{l}6.55(4.61 \text { to } \\
9.30)\end{array}$ & $\begin{array}{l}3.00(0.98 \text { to } \\
5.02)^{4}\end{array}$ \\
\hline Low SEP & $122 / 922$ & $\begin{array}{l}4.39 \text { (3.37 to } \\
5.72)\end{array}$ & $\begin{array}{l}0.26(-1.07 \text { to } \\
1.59)^{\dagger}\end{array}$ & $180 / 1545$ & $\begin{array}{l}8.36(6.05 \text { to } \\
11.55)\end{array}$ & $\begin{array}{l}3.61(1.55 \text { to } \\
5.68)^{\dagger}\end{array}$ \\
\hline \multicolumn{7}{|c|}{ Paternal T2DM } \\
\hline \multicolumn{7}{|l|}{$\begin{array}{l}\text { No paternal } \\
\text { T2DM }\end{array}$} \\
\hline High SEP & $130 / 5835$ & 1.00 (ref) & & $52 / 7555$ & 1.00 (ref) & \\
\hline Medium SEP & $153 / 6849$ & $\begin{array}{l}1.27 \text { (1.00 to } \\
1.61)\end{array}$ & & $82 / 9528$ & $\begin{array}{l}1.32 \text { ( } 0.93 \text { to } \\
1.88)\end{array}$ & \\
\hline Low SEP & $188 / 4614$ & $\begin{array}{l}1.39 \text { (1.10 to } \\
1.75)\end{array}$ & & $191 / 5782$ & $\begin{array}{l}2.53 \text { (1.84 to } \\
3.48)\end{array}$ & \\
\hline \multicolumn{7}{|l|}{ Paternal T2DM } \\
\hline High SEP & $40 / 589$ & $\begin{array}{l}3.11 \text { (2.14 to } \\
4.52)\end{array}$ & & $24 / 836$ & $\begin{array}{l}3.56(2.17 \text { to } \\
5.83)\end{array}$ & \\
\hline Medium SEP & $46 / 746$ & $\begin{array}{l}3.31(2.32 \text { to } \\
4.72)\end{array}$ & $\begin{array}{l}-0.06(-1.58 \text { to } \\
1.45)^{\star}\end{array}$ & $70 / 1370$ & $\begin{array}{l}6.64 \text { ( } 4.60 \text { to } \\
9.59)\end{array}$ & $\begin{array}{l}2.77(0.49 \text { to } \\
5.05)^{*}\end{array}$ \\
\hline Low SEP & $74 / 656$ & $\begin{array}{l}4.86(3.57 \text { to } \\
6.60)\end{array}$ & $\begin{array}{l}1.36(-0.27 \text { to } \\
2.99)^{\dagger}\end{array}$ & $104 / 1058$ & $\begin{array}{l}8.35 \text { (5.90 to } \\
11.82)\end{array}$ & $\begin{array}{l}3.28(0.88 \text { to } \\
5.68)^{\dagger}\end{array}$ \\
\hline
\end{tabular}

ORs are adjusted for age and age-squared.

${ }^{*}$ RERI T2DM for medium SEP.

†RERI T2DM for low SEP.

RERI, relative excess risk due to interaction; SEP, socioeconomic position; T2DM, type 2 diabetes mellitus. 
association studies. ${ }^{41}{ }^{42}$ Family history of T2DM captures both the genetic predisposition for T2DM and the shared environment within a family. This may on the one hand make family history of T2DM a better predictor of T2DM than a GRS, on the other hand it does not allow discrimination between the effects of genes and environment. Although family history of T2DM and a GRS for T2DM both measure T2DM predisposition, future studies should examine if, and to what degree, the use of a GRS would lead to different results compared with this study. In addition, future studies should focus on epigenetic changes related to low SEP as these may play a role in T2DM development. ${ }^{43}$ For example, living in a deprived area has been related to global DNA methylation which in turn has been associated with inflammation markers and cardiovascular disease. ${ }^{44}$ Epigenetic changes related to low SEP might also play a role in T2DM development.

This study has a number of strengths worth mentioning. First, with the large sample size we could precisely estimate associations and interactions of SEP and T2DM family history on T2DM. Second, diagnosis of T2DM was thoroughly assessed using self-reported disease, recorded medication use and, unique for the current sample size, objective measures of both FPG and HbAlc. Third, the clinical risk factors general obesity, abdominal obesity and hypertension were objectively measured. Finally, results are likely to be generalisable to the Dutch population and those of other similar Northern European countries as the Lifelines study population has been shown to be representative for the northern part of The Netherlands. ${ }^{45}$

This study also has some limitations. First, the cross-sectional nature of the data does not allow firm conclusions about causality, pointing to the need for longitudinal studies. Second, we could not discriminate the roles of genes and a shared environment, as we did not have genome-wide genotype data for these participants. Third, we categorised participants using medication with ATC codes A10A and A10B as having T2DM. We might have diagnosed participants as having T2DM while they are actually being treated for pre-diabetes, with metformin (A10B) for example. However, pharmaceutical treatment of pre-diabetes is uncommon in The Netherlands. General practitioners are advised to use lifestyle-related interventions in the treatment of pre-diabetes. Fourth, we had some missing data on behavioural risk factors. This may have resulted in an under-adjustment of the associations and interactions of SEP and T2DM family history with T2DM.

The interaction between low SEP and family history of T2DM that was found in females may support early detection and better-tailored interventions for this specific group of women. Future studies need to investigate whether interventions targeted specifically at low-SEP females with T2DM family history contribute to a reduction of T2DM-related morbidity and mortality. Prevention and intervention strategies should include both individual (eg, health behaviour) and contextual factors (eg, food availability). Prevention and intervention efforts should further take into account that people with a low SEP often have low health literacy. ${ }^{46}$ Low health literacy may hamper the translation of knowledge about risk factors into healthy behaviour. Future studies should further examine contributing pathways for the interaction effect in females, as this may offer insight into which behavioural or clinical risk factors are most important to target at in this specific group of women. Despite the higher relative risk of T2DM for females, the absolute risk for T2DM was highest for males. This additionally points to the need for improvement of early detection and interventions in males.

We conclude that low SEP and family history of T2DM are independently associated with T2DM, and more importantly, exacerbate each other's impact on T2DM in females but not in males. Behavioural and clinical risk factors mostly explain this interaction, but threefold risks remain in both males and females with low SEP in combination with a family history of T2DM. The exacerbation by low SEP of T2DM risks in T2DM families deserves attention in prevention and community care.

Acknowledgements The authors wish to acknowledge the services of the Lifelines Cohort Study, the contributing research centres delivering data to Lifelines and all the study participants.

Contributors SZ, HS, UB and SR conceived the study. SZ analysed the data and wrote the initial draft. HS, UB and SR contributed to the conception and design of the initial draft. All authors made substantial contributions to the final draft and approved its submission.

Funding The Lifelines Cohort Study, and generation and management of GWAS genotype data for the Lifelines Cohort Study is supported by the Netherlands Organization of Scientific Research NWO (grant 175.010.2007.006), the Ministry of Economic Affairs, the Ministry of Education, Culture and Science, the Ministry for Health, Welfare and Sports, the Northern Netherlands Collaboration of Provinces (SNN), the Province of Groningen, University Medical Center Groningen, the University of Groningen, Dutch Kidney Foundation and Dutch Diabetes Research Foundation.

Competing interests None declared.

Ethics approval Medical Ethics Committee of the University Medical Center Groningen.

Provenance and peer review Not commissioned; externally peer reviewed.

Data sharing statement Lifelines is a facility that is open for all researchers. Information on application and data access procedure is summarised on www. lifelines.net.

Open Access This is an Open Access article distributed in accordance with the Creative Commons Attribution Non Commercial (CC BY-NC 4.0) license, which permits others to distribute, remix, adapt, build upon this work non-commercially, and license their derivative works on different terms, provided the original work is properly cited and the use is non-commercial. See: http://creativecommons.org/ licenses/by-nc/4.0/

(C) Article author(s) (or their employer(s) unless otherwise stated in the text of the article) 2017. All rights reserved. No commercial use is permitted unless otherwise expressly granted.

\section{REFERENCES}

1. Danaei G, Finucane MM, Lu Y, et al; Global Burden of Metabolic Risk Factors of Chronic Diseases Collaborating Group (Blood Glucose). National, regional, and global trends in fasting plasma glucose and diabetes prevalence since 1980: systematic analysis of health examination surveys and epidemiological studies with 370 countryyears and $2 \cdot 7$ million participants. Lancet 2011;378:31-40. 
2. Shaw JE, Sicree RA, Zimmet PZ. Global estimates of the prevalence of diabetes for 2010 and 2030. Diabetes Res Clin Pract 2010;87:4-14.

3. Murray CJ, Vos T, Lozano R, et al. Disability-adjusted life years (DALYs) for 291 diseases and injuries in 21 regions, 1990-2010: a systematic analysis for the global burden of disease study 2010. Lancet 2012;380:2197-223.

4. Wikström K, Lindström J, Tuomilehto J, et al. Socio-economic differences in Dysglycemia and lifestyle-related risk factors in the Finnish middle-aged population. Eur J Public Health 2011;21:768-74.

5. Williams ED, Tapp RJ, Magliano DJ, et al. Health behaviours, socioeconomic status and diabetes incidence: the Australian diabetes obesity and lifestyle study (AusDiab). Diabetologia 2010;53:2538-45.

6. Agardh EE, Ahlbom A, Andersson T, et al. Explanations of socioeconomic differences in excess risk of type 2 diabetes in Swedish men and women. Diabetes Care 2004;27:716-21.

7. Stringhini S, Tabak AG, Akbaraly TN, et al. Contribution of modifiable risk factors to social inequalities in type 2 diabetes: prospective Whitehall II Cohort study. BMJ 2012;345:e5452.

8. Agardh E, Allebeck P, Hallqvist J, et al. Type 2 diabetes incidence and socio-economic position: a systematic review and metaanalysis. Int J Epidemiol 2011;40:804-18.

9. Lyssenko V, Jonsson A, Almgren P, et al. Clinical risk factors, DNA variants, and the development of type 2 diabetes. $N$ Engl J Med 2008;359:2220-32.

10. Wilson PW, Meigs JB, Sullivan L, et al. Prediction of incident diabetes mellitus in middle-aged adults: the Framingham offspring study. Arch Intern Med 2007;167:1068-74.

11. van 't Riet E, Dekker JM, Sun Q, et al. Role of adiposity and lifestyle in the relationship between family history of diabetes and 20 year incidence of type 2 diabetes in U.S. women. Diabetes Care 2010;33:763-7.

12. Scott RA, Langenberg C, Sharp SJ, et al; InterAct Consortium. The link between family history and risk of type 2 diabetes is not explained by anthropometric, lifestyle or genetic risk factors: the EPIC-InterAct study. Diabetologia 2013;56:60-9.

13. Hilding A, Eriksson AK, Agardh EE, et al. The impact of family history of diabetes and lifestyle factors on abnormal glucose regulation in middle-aged Swedish men and women. Diabetologia 2006;49:2589-98.

14. Kivimäki M, Lawlor DA, Davey Smith G, et al. Socioeconomic position, co-occurrence of behavior-related risk factors, and coronary heart disease: the Finnish public sector study. Am J Public Health 2007;97:874-9.

15. Schuit AJ, van Loon AJ, Tijhuis M, et al. Clustering of lifestyle risk factors in a general adult population. Prev Med 2002;35:219-24.

16. Drong AW, Lindgren CM, McCarthy MI. The genetic and epigenetic basis of type 2 diabetes and obesity. Clin Pharmacol Ther 2012;92:707-15

17. Kumari M, Head J, Marmot M. Prospective study of social and other risk factors for incidence of type 2 diabetes in the Whitehall II study. Arch Intern Med 2004;164:1873-80.

18. Maty SC, Everson-Rose SA, Haan MN, et al. Education, income, occupation, and the 34-year incidence (1965-99) of type 2 diabetes in the Alameda county study. Int J Epidemiol 2005;34:1274-81

19. Ahlbom A, Alfredsson L. Interaction: a word with two meanings creates confusion. Eur J Epidemiol 2005;20:563-4.

20. Kahn SE, Cooper ME, Del Prato S. Pathophysiology and treatment of type 2 diabetes: perspectives on the past, present, and future. Lancet 2014;383:1068-83.

21. Mauvais-Jarvis F. Sex differences in metabolic homeostasis, diabetes, and obesity. Biol Sex Differ 2015;6 14.
22. Scholtens S, Smidt N, Swertz MA, et al. Cohort profile: LifeLines, a three-generation cohort study and biobank. Int J Epidemiol 2015;44:1172-80.

23. American Diabetes Association. Diagnosis and classification of diabetes mellitus. Diabetes Care 2014;37(Suppl 1):S81-90.

24. WHO collaborating centre for drug statistics methodology. ATC/DDD index. 2016 http://www.whocc.no/atc_ddd_index/ (Accessed 14 Nov 2016).

25. Amini M, Bashirova D, Prins BP, et al; LifeLines Cohort Study. Eosinophil count is a common factor for complex metabolic and pulmonary traits and diseases: the LifeLines Cohort study. PLoS One 2016;11:e0168480.

26. Meems LM, de Borst MH, Postma DS, et al. Low levels of vitamin D are associated with multimorbidity: results from the LifeLines Cohort study. Ann Med 2015;47:474-81.

27. OECD, European Union. UNESCO institute for statistics. ISCED 2011 operational manual: guidelines for classifying national education programmes and related qualifications: OECD publishing, 2015.

28. Slagter SN, van Vliet-Ostaptchouk JV, Vonk JM, et al. Combined effects of smoking and alcohol on metabolic syndrome: the LifeLines Cohort study. PLoS One 2014;9:e96406.

29. World Health Organization. Waist circumference and Waist-Hip ratio: report of a WHO expert consultation. 2008

30. Messerli FH, Williams B, Ritz E. Essential hypertension. Lancet 2007;370:591-603.

31. Knol MJ, VanderWeele TJ. Recommendations for presenting analyses of effect modification and interaction. Int $J$ Epidemiol 2012;41:514-20.

32. Kendler KS, Gardner CO. Interpretation of interactions: guide for the perplexed. Br J Psychiatry 2010;197:170-1.

33. Andersson T, Alfredsson L, Källberg $\mathrm{H}$, et al. Calculating measures of biological interaction. Eur J Epidemio/ 2005;20:575-9.

34. Hosmer DW, Lemeshow S. Confidence interval estimation of interaction. Epidemiology 1992;3:452-6.

35. Chen E, Miller GE. Socioeconomic status and health: mediating and moderating factors. Annu Rev Clin Psychol 2013;9:723-49.

36. Tamres LK, Janicki D, Helgeson VS. Sex differences in coping behavior: a Meta-Analytic review and an examination of relative coping. Personality and Social Psychology Review 2002;6:2-30

37. Kelly SJ, Ismail M. Stress and type 2 diabetes: a review of how stress contributes to the development of type 2 diabetes. Annu Rev Public Health 2015;36:441-62.

38. Galobardes B, Lynch J, Smith GD. Measuring socioeconomic position in health research. Br Med Bull 2007;81-82:21-37.

39. Vart P, Gansevoort RT, Coresh J, et al. Socioeconomic measures and CKD in the United States and The Netherlands. Clin J Am Soc Nephrol 2013;8:1685-93.

40. Breton MC, Guénette L, Amiche MA, et al. Burden of diabetes on the ability to work: a systematic review. Diabetes Care 2013;36:740-9.

41. Meigs JB, Shrader P, Sullivan LM, et al. Genotype score in addition to common risk factors for prediction of type 2 diabetes. $N$ Engl $J$ Med 2008;359:2208-19.

42. Mühlenbruch $\mathrm{K}$, Jeppesen $\mathrm{C}$, Joost HG, et al. The value of genetic information for diabetes risk prediction - differences according to sex, age, family history and obesity. PLoS One 2013;8:e64307.

43. Loi M, Del Savio L, Stupka E. Social epigenetics and equality of opportunity. Public Health Ethics 2013;6:142-53.

44. McGuinness D, McGlynn LM, Johnson PC, et al. Socio-economic status is associated with epigenetic differences in the pSoBid Cohort. Int J Epidemiol 2012;41:151-60.

45. Klijs B, Scholtens S, Mandemakers JJ, et al. Representativeness of the LifeLines Cohort Study. PLoS One 2015;10:e0137203.

46. van der Heide I, Rademakers J, Schipper M, et al. Health literacy of Dutch adults: a cross sectional survey. BMC Public Health 2013;13:179. 